\title{
Primary Fibrosarcoma of the Liver: We Don't Know Much
}

\author{
A Case Report
}

\author{
Sadaf Ali Parveen Shah Umer Javed Shah Azra Shah \\ Showkat Zargar Atthar Bashir Sunil Dhar Muzzafar Ali \\ Department of Surgical Gastroentrology, SK Institute of Medical Sciences, Soura, \\ Srinagar, Jammu and Kashmir, Srinagar, India
}

\section{Key Words}

Primary fibrosarcoma · Liver · Presentation · Pathology

\begin{abstract}
A 60-year-old lady presented to us with a right upper abdominal mass. With a clinical diagnosis of liver tumor, she was evaluated with abdominal CT, MRI, nuclear scan, tumor markers, USG guided FNAC and other baseline investigations. On evaluation she had a massive right lobe tumor crossing the midline. In view of the ambiguous diagnosis she was subjected to laparotomy where the lesion was judged unresectable and a biopsy was taken. Histopathological examination showed the rare pathology of primary fibrosarcoma of the liver with features of homogeneous, spindle-shaped cells with abundant collagen fibers showing a classic herringbone pattern. Tissue samples were then sent to another referral cancer hospital for immunohistochemistry and immunoreactive vimentin was found in the tumor cells. Electron microscopically, the tumor cells were rich in rough endoplasmic reticulum without a basement membrane, and were surrounded by large amounts of collagen fibers. The fibroblastic character of the tumor cells was suggested by light and electron microscopy.
\end{abstract}

\section{Case Report}

A 60-year-old lady presented to our sister department of Medical Gastroenterology at a tertiary health care institute with a history of an increasing mass in the right upper abdomen of one and a half year duration. She also had a history of weight loss due to early satiety and decreasing appetite. She had been evaluated with abdominal CECT 14 months before by some local doctor which had shown a mass lesion in the right lobe of the liver. She had not seen any doctor subsequently for further workup.

General physical examination revealed that the patient was cachectic with mild pallor. All her systemic examinations were normal except a big nodular mass in the right hypochondrium merging with the liver. The Department of Medical Gastroenterology considered her for a repeat workup, with abdominal MRI, RBC trigged nuclear scan of the liver, serum tumor markers and routine base 
investigations. MRI showed a nodular mass lesion arising from the right lobe of the liver, crossing towards the left lobe with involvement of the right portal vein, with areas of cystic changes and hemorrhage within the lesion (fig. 1). Nuclear scan subsequently ruled out the possibility of a vascular origin of the tumor. Her tumor markers, including $\alpha$-fetoprotein, CEA, CA 19-9 and $\beta$ HCG, were all within normal limits. She was also subjected to upper and lower gastrointestinal endoscopy to rule out any occult primary lesion in the gastrointestinal tract. Routine laboratory investigations including liver function tests, hemogram, kidney function, chest X-ray and ECG were within fairly normal limits, her coagulogram revealing PT elevated by $3 \mathrm{~s}$. Serology was negative for hepatitis B and C. She was also subjected to USG guided FNAC which was inconclusive and revealed only blood cells.

After complete workup with a tentative diagnosis of fibrolamellar hepatocellular carcinoma the patient was referred to our department for surgical intervention. She was offered a diagnostic and if possible curative laparotomy after repeat imaging (abdominal CECT) as she had again lapsed a period of 3-4 months after her workup. Due to monitoring constraints, her attenders did not agree to get an abdominal CT but were ready for any possible surgical intervention with the minimum of a biopsy to plan further treatment.

On exploration the patient was found to have nodular bilobular disease occupying almost all of the liver. These nodules were grossly greyish white in appearance (fig. 2 , fig. 3 ). There were areas of boggy swelling in between firm nodules predominantly on the inferior surface of liver suggestive of bleeding within the tumor on aspiration. The lesion involving both lobes of the liver was too big and multicentric for any resectional procedure and so a biopsy from the lesion was taken safely. Her postoperative period was uneventful. After getting her histopathological report the patient was referred to a medical oncologist for further treatment.

The histopathology report revealed a rare pathology of primary fibrosarcoma of the liver. This is the first case of fibrosarcoma of the liver reported at our institute. On light microscopy the tumor revealed homogeneous, spindle-shaped cells with abundant collagen fibers showing a classic herringbone pattern (fig. 4). Tissue samples were then sent to another referral cancer hospital for immunohistochemistry where immunoreactive vimentin was found in the tumor cells. Electron microscopically, the tumor cells were rich in rough endoplasmic reticulum without a basement membrane and were surrounded by large amounts of collagen fibers. The fibroblastic character of the tumor cells was suggested by light and electron microscopy.

\section{Discussion}

Sarcomatous tumors commonly occur in the retroperitoneum of the abdomen. The various types of sarcomas include angiosarcomas, liomyosarcomas, liposarcomas and fibrosarcomas. The purpose of this case report is to share information on a rare tumor of the liver, a primary fibrosarcoma, as up to the late seventies the literature about this entity was restricted to autopsy diagnosis [1]. To our knowledge there are case reports from various parts of the world $[2,3]$, but there are no series of cases of primary fibrosarcoma of the liver. Etiologically exposure to cadmium has been linked to carcinogenesis of this disease in animal models [4]. Poggio et al. described a series of 20 cases of sarcomatous tumors of the liver, of which angiosarcoma was the commonest, and concluded that primary treatment is surgery with survival depending on the degree of differentiation [5].

From the available literature, primary treatment to be considered for fibrosarcoma of the liver is surgery with curative intent. In a recent article from Sloan-Kettering Cancer Center, between 1981 and 2004 they identified only 30 cases of primary liver sarcomas of which most cases (10) were hemangioendotheliomas and only 3 were diagnosed to be primary fibrosarcoma. Only 11 of these patients underwent $\mathrm{R} 0$ resection and this group of resected tumors had a 5-year survival rate of $65 \%$ [6]. Unfortunately our patient presented quite late in the course of disease even if we consider her first CT scan done one and a half year back. Clinically these patients present with pain and constitutional symptoms. There is a report of one patient with primary fibrosarcoma presenting with frequent episodes of 


\begin{tabular}{r|l|l|l} 
Case Reports $/ \mathrm{h}$ & $\begin{array}{l}\text { Case Rep Gastroenterol 2008;2:384-389 } \\
\text { D0I: 10.1159/000161563 }\end{array}$ & Published online: November 8, 2008 & $\begin{array}{l}\text { O 2008 S. Karger AG, Basel } \\
\text { ISSN 1662-0631 } \\
\text { www.karger.com/crg }\end{array}$ \\
\hline
\end{tabular}

hypoglycemia, where insulin-like growth factor II was intensely stained in the Golgi area of the tumor cells, suggesting its role in the mechanism of hypoglycemia [7].

On histopathological examination these neoplasms show typical light microscopic features like that of malignant rhabdoid tumor with filamentous cytoplasmic inclusions (fig. 4), and on electron microscopic examination show staining for both cytokeratin and vimentin by immunohistochemistry [8]. After making a diagnosis of primary fibrosarcoma of the liver at an inoperable stage, an extensive review of the literature regarding the role of other treatment modalities was done which was not encouraging $[5,8]$. Though few reports recommend chemotherapy [9] in liver metastasis of retroperitoneal fibrosarcoma consisting of cyclophosphamide, vincristine, farmorubicin, and dacarbazine, there is no definite role as treatment for primary lesion of liver. Overall the prognosis reported by most of the authors is dismal $[1-3,10]$.

We conclude by passing on the message that this rare entity does exist and is an area for workup to make guidelines for management of such tumors. This may be one of the few reported cases of primary hepatic fibrosarcoma confirmed by immunohistochemistry and electron microscopy.

Fig. 1. MRI of the lesion.

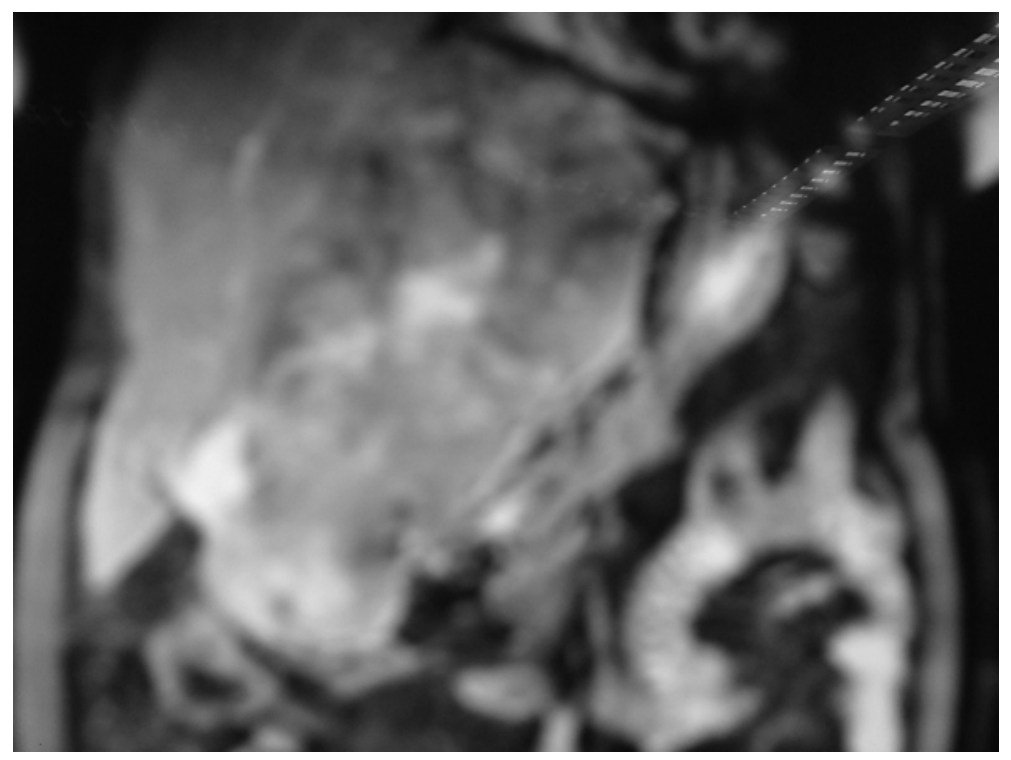




\begin{tabular}{r|l|l|l} 
Case Reports in & $\begin{array}{l}\text { Case Rep Gastroenterol 2008;2:384-389 } \\
\text { D0I: 10.1159/000161563 }\end{array}$ & Published online: November 8, 2008 & $\begin{array}{l}\text { O 2008 S. Karger AG, Basel } \\
\text { ISSN 1662-0631 } \\
\text { www.karger.com/crg }\end{array}$ \\
\hline
\end{tabular}

Fig. 2. Typically greyish white nodular lesion found on surgery.

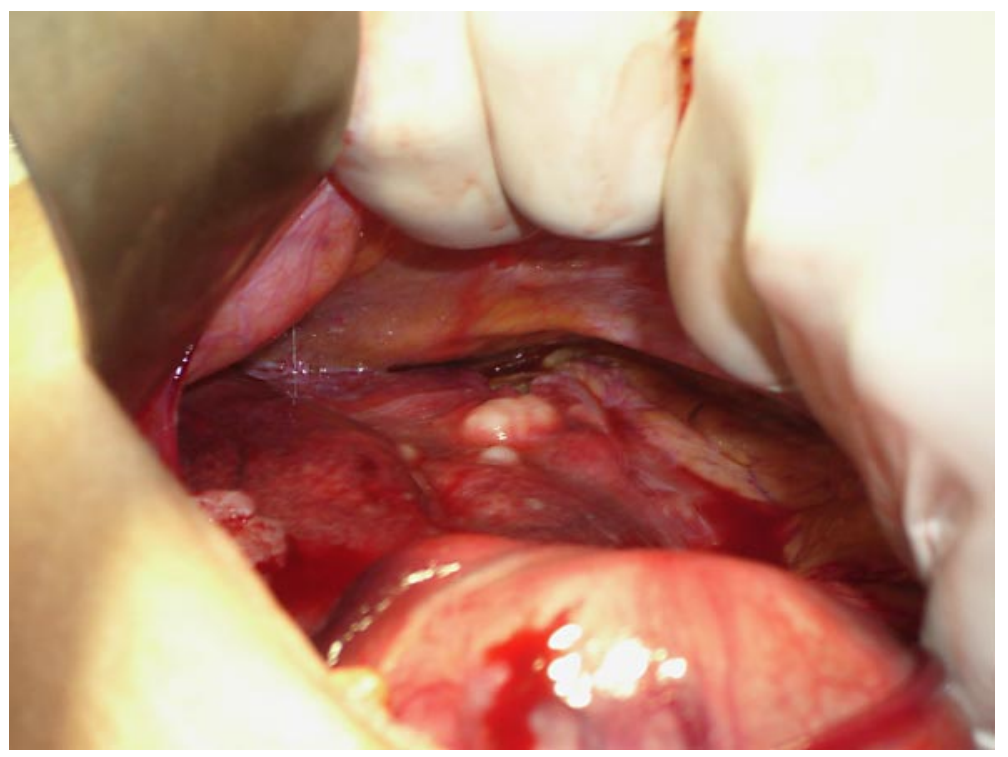

Fig. 3. Largest nodule involving the right lobe of the liver (operative picture).

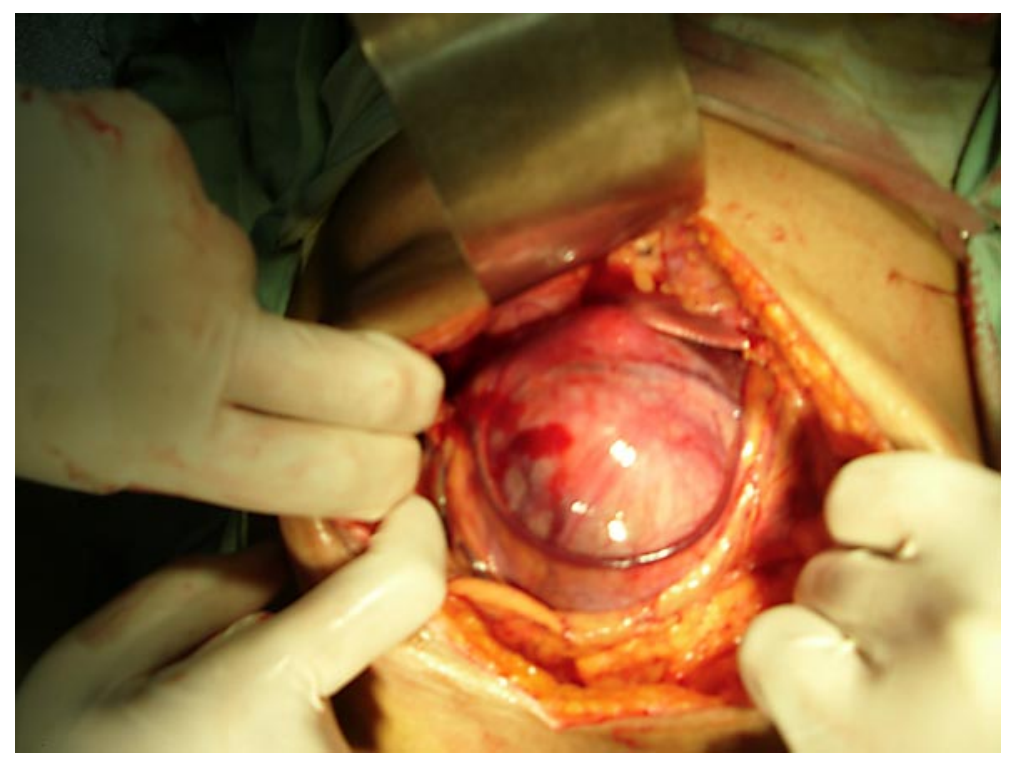




\begin{tabular}{r|l|l|l} 
Case Reports $/ \mathrm{h}$ & $\begin{array}{l}\text { Case Rep Gastroenterol 2008;2:384-389 } \\
\text { D0I: 10.1159/000161563 }\end{array}$ & Published online: November 8, 2008 & $\begin{array}{l}\text { O 2008 S. Karger AG, Basel } \\
\text { ISSN 1662-0631 } \\
\text { www.karger.com/crg }\end{array}$ \\
\hline
\end{tabular}

Fig. 4. Typical features of liver fibrosarcoma.

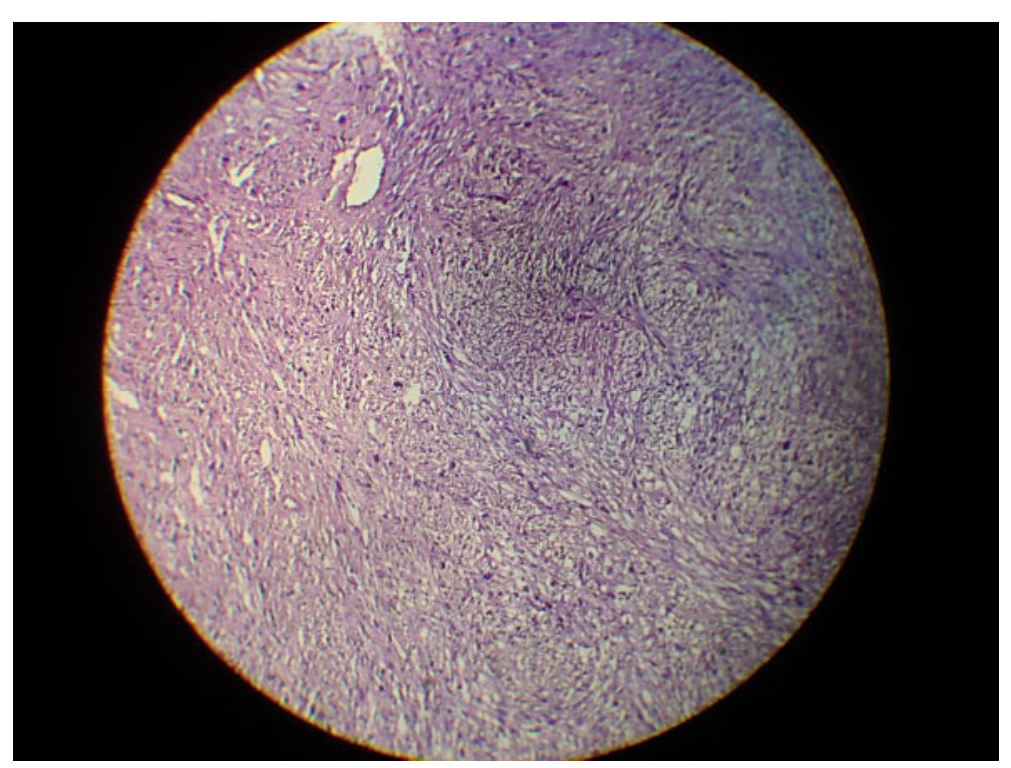




\section{References}

1 Alrenga DP: Primary fibrosarcoma of the liver. Case report and review of the literature. Cancer 1975;36:446-449.

-2 Nakahama M, Takanashi R, Yamazaki I, Machinami R: Primary fibrosarcoma of the liver. Immunohistochemical and electron microscopic studies. Acta Pathol Jpn 1989;39:814-820.

-3 Ito Y, Uesaka Y, Takeshita S, et al: A case report of primary fibrosarcoma of the liver. Gastroenterol Jpn 1990;25:753-757.

4 Waalkes MP, Rehm S, Cherian MG: Repeated cadmium exposures enhance the malignant progression of ensuing tumors in rats. Toxicol Sci 2000;54:110-120.

5 Poggio JL, Nagorney DM, Nascimento AG, et al: Surgical treatment of adult primary hepatic sarcoma. Br J Surg 2000;87:1500-1505.

-6 Weitz J, Klimstra DS, Cymes K, et al: Management of primary liver sarcomas. Cancer 2007;109:1391-1396.

7 Kotani K, Tsuji M, Oki A, et al: IGF-II producing hepatic fibrosarcoma associated with hypoglycemia. Intern Med 1993;32:897-901.

8 Hunt SJ, Anderson WD: Malignant rhabdoid tumor of the liver. A distinct clinicopathologic entity. Am J Clin Pathol 1990;94:645-648.

-9 Isobe H, Wada Y, Ryo J, et al: An effective chemotherapy regimen for liver metastasis from retroperitoneal fibrosarcoma: report of a case. Surg Today 1997;27:463-465.

10 Kelle S, Paetsch I, Neuss M, et al: Primary fibrosarcoma of the liver infiltrating the right atrium of the heart. Int J Cardiovasc Imaging 2005;21:655-658. 